\title{
Numerical Study of the Combustion of CH4-C3H8/ Air: Application to a Combustion Chamber with Two Coaxial Jets
}

\author{
Mohamed El Hadi Attia ${ }^{1}$, Zied Driss ${ }^{2}$, Abderrahmane Khechekhouche ${ }^{2,3}$ \\ ${ }^{1 *}$ Department of Physics, Faculty of Science, University of El Oued, 39000 El Oued, ALGERIA \\ ${ }^{2}$ Laboratory of Electro-Mechanic Systems (LASEM), ENIS, University of Sfax, TUNISIA \\ 3 Renewable energy development unit in arid zones (UDERZR), El-Oued University, ALGERIA
}

attiameh@gmail.com

\begin{abstract}
In this study, we studied numerically the non-premixed combustion provided by two coaxial methane-propane/air jets in a 3D cylindrical combustion chamber. To study this kind of phenomenon we used a special treatment of the mathematical model and we chose two models of computation PDF and LES. In order to find the aero-thermo-chemical characteristics in the burner, namely: axial velocity, temperature and mass fraction of carbon monoxide CO. Using commercial calculation software CFD Fluent The objective of this work is to research the fuel that reduces the emission of carbon monoxide $\mathrm{CO}$, which is considered a gas toxic to the environment, by comparing the two fuels $\mathrm{CH}_{4}$ and $\mathrm{C}_{3} \mathrm{H}_{8}$. The results give methane fuel reduces carbon monoxide as a pollutant chemical species in combustion products compared to propane fuel.
\end{abstract}

Keywords: Non-Premixed Combustion; Methane; Propane; Numerical Simulation CFD

Received: 12/10/2017 - Accepted: 15/11/2017

\section{Introduction}

Combustion control is a vital capacity in the development of new industrial systems, such as propulsion systems. One of the challenges that industry must face today in order to accompany technological development is to reduce the impact of combustion on the environment. This impact is manifested in the discharge of chemical pollutants, of which the oxides of nitrogen (NOx) and the gases participating in the greenhouse effect, such as carbon oxides, $\mathrm{CO}$ and $\mathrm{CO}_{2}$, are in the forefront. This challenge forces engine manufacturers to propose increasingly innovative solutions to achieve the set objectives [1].

Several projects aim to minimize these emissions by introducing techniques such as lean burning, combustion of fuels of renewable origin and which does not contain carbon. Combustion is a very complex phenomenon and its experimental investigation poses many difficulties. Therefore, the experimental approach remains costly and limited to certain operating conditions. However, numerical calculation can be the most appropriate solution, given the progress made in the field of computing and modeling. There are several simulation models, either to simulate only the flow, or to simulate it by associating other joint phenomena [2].

In this work, a simulation study of the combustion of methane and propane in a combustion chamber. In addition, we used mathematical models, especially LES for dynamic parameters and PDF for thermochemical parameters to reduce the number of equations, we used FLUENT-CFD. Considering that the study of the behavior of non-premixed combustion fueled by $\mathrm{CH}_{4}$ and $\mathrm{C}_{3} \mathrm{H}_{8}$ fuels consists of three parameters: axial velocity, temperature and mass fraction of carbon monoxide $\mathrm{CO}$. The objective of this research is compared the fuels $\mathrm{CH}_{4}$ and $\mathrm{C}_{3} \mathrm{H}_{8}$ to find the fuel that reduces the emission of carbon monoxide $\mathrm{CO}$, which is considered the most toxic gas to the environment. The results give methane fuel reduces carbon monoxide as a pollutant chemical species in combustion products compared to propane fuel.

\section{EXPERIMENTAL CONFIGURATION}

The configuration is a burner is given in figure 1 . The cylindrical combustion chamber of radius $\mathrm{R} 4=61.15 \mathrm{~mm}$ and length $\mathrm{L}=1 \mathrm{~m}$ provided by two coaxial jets $\mathrm{CH}_{4}$ $\mathrm{C}_{3} \mathrm{H}_{8}$ /air, the central jet presents by an internal radius equal to $\mathrm{R} 1=31.57 \mathrm{~mm}$ and an external radius $\mathrm{R} 2=31.75$ $\mathrm{mm}$, which injects the fuel with a speed V1=0.9278 m/s and the temperature $\mathrm{T} 1=300 \mathrm{~K}$. and the annular jet has an internal radius equal to $\mathrm{R} 3 \equiv \mathrm{R}=46.85 \mathrm{~mm}$, which injects air at a speed $\mathrm{V} 2=20.63 \mathrm{~m} / \mathrm{s}$ and preheated to a temperature $\mathrm{T} 2=750 \mathrm{~K}$. The combustion chamber is pressurized at $\mathrm{p}=3.8$ bar and has a wall at constant temperature of partition $\mathrm{T}=500 \mathrm{~K}[3-8]$. 


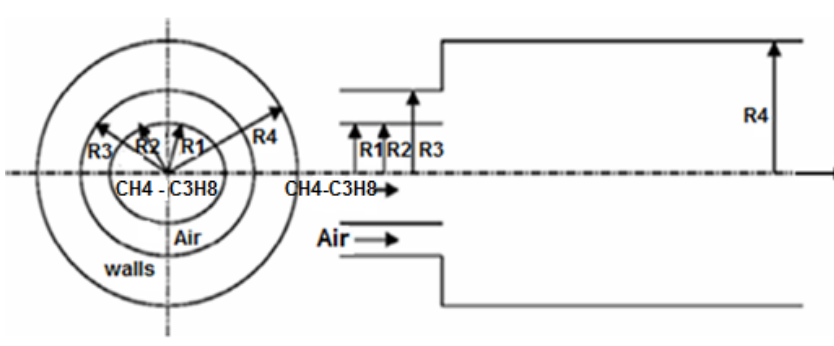

Figure. 1 Schematic of the burner

\section{GOVERNING EQUATIONS}

In this paper, we study the behavior of non-premixed turbulent combustion in three dimensions using numerical simulation. We can write the control equations for the compressible flow in Cartesian coordinates as follows [38]:

Continuity:

$\frac{\partial \bar{\rho}}{\partial t}+\frac{\partial}{\partial x_{i}}\left(\bar{\rho} \tilde{u}_{i}\right)=0$

(1)

Momentum:

$\frac{\partial \bar{\rho} \tilde{u}_{i}}{\partial t}+\frac{\partial}{\partial x_{i}}\left(\bar{\rho} \tilde{u}_{i} \tilde{u}_{j}\right)=-\frac{\partial}{\partial x_{i}}\left[\bar{\rho}\left(\overline{u_{i} u_{j}}-\tilde{u}_{i} \tilde{u}_{j}\right)\right]-\frac{\partial \bar{p}}{\partial x_{j}}+\frac{\partial \overline{\tau_{i j}}}{\partial x_{i}}$

(2)

Energy:

$\frac{\partial}{\partial t} \bar{\rho} \tilde{h}+\frac{\partial}{\partial x_{i}}\left(\bar{\rho} \tilde{u}_{i} \tilde{h}\right)=-\frac{\partial}{\partial x_{i}}\left[\bar{\rho}\left(\overline{u_{i} h}-\tilde{u}_{i} \tilde{h}\right)\right]+\frac{\partial \bar{p}}{\partial t}+\frac{\partial}{\partial x_{i}} \overline{u_{j} \tau_{i j}}$

(3)

Species:

$\frac{\partial}{\partial t} \bar{\rho} \widetilde{Y}_{f}+\frac{\partial}{\partial x_{i}}\left(\bar{\rho} u_{i} \widetilde{Y}_{f}\right)=-\frac{\partial}{\partial x_{i}}\left[\bar{\rho}\left(\overline{u_{i} Y_{f}}-\widetilde{u}_{i} \widetilde{Y}_{f}\right)\right]+\overline{\dot{\omega}}_{f}$

(4)

Where:

$\mathrm{i}=1,2,3$ and $\mathrm{j}=1,2,3, \bar{\rho}, \tilde{u}_{i}, \bar{\omega}_{i}, t$ are density, velocity vector, fuel reaction rate and time respectively. Thermodynamic state:

\section{$\bar{p}=\bar{\rho} R_{m} \widetilde{T}$}

(5)

- Unresolved Reynolds stresses $\left(\overline{\boldsymbol{u}_{i} \boldsymbol{u}_{j}}-\tilde{\boldsymbol{u}}_{i} \tilde{\boldsymbol{u}}_{j}\right)$, requiring a subgrid scale turbulence model.

- Unresolved species fluxes $\left(\overline{\boldsymbol{u}_{i} \boldsymbol{Y}_{f}}-\widetilde{\boldsymbol{u}}_{\boldsymbol{i}} \tilde{Y}_{f}\right)$ and enthalpy fluxes $\left(\overline{u_{i} h}-\tilde{u}_{i} \tilde{h}\right)$ requiring a probability density function (PDF) approach.

- Filtered chemical reaction rate by $\overline{\dot{\omega}}_{f}$.

The tensor of the unsolved constraints $\tau_{i j}$ as the tensor velocity of deformation $\widetilde{S}_{i j}$ for subgrid models by the intermediary of a turbulent viscosity $\left(\boldsymbol{v}_{t}\right)$, and a subgrid kinetic energy $\left(k_{l l}\right)$. Therefore, we focus on the assumption of Boussinesq in which the small scales influence the large scales via the subgrid-scale stress [18]:

$$
\tau_{i j}=2 \bar{\rho} v_{t} \tilde{S}_{i j}-\frac{1}{3} k_{l l} \delta_{i j}
$$

(6)

Where, the filtered strain rate tensor is defined by:

$\tilde{S}_{i j}=\frac{1}{2}\left(\frac{\partial \tilde{u}_{i}}{\partial x_{j}}+\frac{\partial \tilde{u}_{j}}{\partial x_{i}}\right)-\frac{1}{3} \tilde{u}_{l l} \delta_{i j}$

The use of this WALE-eddy viscosity model to express the eddy viscosity term in the momentum equation (2) is motivated by:

- Recovering the proper behavior of the eddy viscosity near the wall in the case of the wall-bounded flows;

- Preserving the interested properties such as the capacity to provide no eddy-viscosity in the case of vanishing turbulence (property required for the transition from laminar to turbulent states);

- Relying on the fact that no information about the direction and distance from the wall are needed (avoiding the use of any damping function);

- Being suitable for unstructured grids, where evaluating a distance to the wall is precarious.

The residual stress tensor of the WALE eddy viscosity model can be found as [3-8]:

$v_{t}=\left(C_{w} \Delta\right)^{2} \frac{\left(s_{i j}^{d} s_{i j}^{d}\right)^{3 / 2}}{\left(\tilde{s}_{i j} \tilde{s}_{i j}\right)^{5 / 2}+\left(s_{i j}^{d} s_{i j}^{d}\right)^{5 / 4}}$

where

$$
s_{i j}^{d}=\frac{1}{2}\left(\widetilde{g}_{i j}^{2}+\widetilde{g}_{j i}^{2}\right)-\frac{1}{3} \widetilde{g}_{k k}^{2} \delta_{i j}
$$

and

$$
\tilde{g}_{i j}=\frac{\partial \tilde{u}_{i}}{\partial x_{j}}
$$

$C w$ : is the WALE model constant $(C w=0.49)$. The model constants used for all the computations in this paper have been set up for academic configurations such as turbulent combustion and homogenous isotropic turbulence [1-8]. And, $\Delta$ is the spatial filter width.

The statistical distribution function of the mixture fraction performs much better than the commonly used subgrid scale models perform for the mixture fraction variance. Therefore, the mixture fraction is considered as the scalar variable [1-8]:

$\tilde{y}=\int_{Z=0}^{1} y(Z) \tilde{P}(Z) d Z$

(11)

With a simple global reaction rate, non-premixed combustion can be presented by a reactant mass fraction $Y_{f}(\vec{x}, t)$, which is described in (4) [1-8].

For non-premixed combustion, additional scalar variable of mixture fraction $\tilde{Z}(\vec{x}, t)$ is needed. The transport equation of mixture fraction is such as:

$\frac{\partial}{\partial t} \bar{\rho} \tilde{Z}+\frac{\partial}{\partial x_{i}}\left(\bar{\rho} u_{i} \tilde{Z}\right)=\frac{\partial}{\partial x_{i}}\left(\bar{\rho} D \frac{\partial}{\partial x_{i}} \tilde{Z}\right)$

The above two equations can be combined to be applied in whichever premixed, partially premixed, or 
non-premixed flames [1-8]. In the case of simple global reaction rate, progress variable $\tilde{c}(\vec{x}, t)$ is often used instead of $\widetilde{Y}_{f}(\vec{x}, t)$ for convenience. In the thin premixed flame, progress variable changes from zero to unity. And with progress variable and mixture fraction, lean reactant mass fraction can be defined by:

$\tilde{Y}_{f}(\vec{x}, t) \quad=\quad Y_{\phi} \quad[\tilde{c}(\vec{x}, t), \quad \tilde{Z}(\vec{x}, t)]$ (13)

But for the premixed combustion with coflow of air or pilot product, following equation can be applied to express the lean reactant mass fraction [1-8],

$\tilde{Y}_{f}(\vec{x}, t)=Y_{\phi} \cdot \tilde{Z}(\vec{x}, t) \cdot[1-c(\vec{x}, t)]$

(14)

$Y_{\phi}$ is the mass fraction of fuel in the main fuel/air mixture inflow.

For the unburnt reactants $\tilde{Z}=1$ and $\tilde{c}=0$;

For the burnt product $\tilde{z}=0$ and $\tilde{c}=1$.

For homogenous combustion $\tilde{z}(\vec{x}, t)$, the equation (14) is reduced to traditional progress variable equation for non-premixed combustion [1-8]:

$\frac{\partial \bar{\rho} \tilde{c}}{\partial t}+\frac{\partial}{\partial x_{i}}\left(\bar{\rho} \tilde{u}_{i} \tilde{c}\right)=-\frac{\partial}{\partial x_{i}} \tau_{c}+\frac{\partial}{\partial x_{i}} \cdot\left(\bar{\rho} D \frac{\partial}{\partial x_{i}} \tilde{c}\right)+\overline{\rho \dot{\omega}_{c}}$

In this work, the PDF method is employed as a subgrid scale (SGS) closure in LES of a turbulent nonpremixed combustion of methane-hydrogen/air. The joint probability density function of the SGS scalars is determined via the solution of its modeled transport equation.

These LES and PDF models are already validated in previous work [3-8].

\section{RESUlTS AND DISCUSSION "COMPARISON OF $\mathrm{CH}_{4}$ $\& \mathrm{C}_{3} \mathrm{H}_{8} "$}

The LES models and the PDF approach explained and detailed in previous work [3-8]. Then the parameters: axial velocity, temperature and mass fraction of carbon monoxide are also used to control the flame behavior supplied by the $\mathrm{CH}_{4}$ or $\mathrm{C}_{3} \mathrm{H}_{8}$. Moreover, the presentation and comparison of results are based on normalizing length and velocity by using, respectively, the injector radius $(\mathrm{R} \equiv \mathrm{R} 3)$ and the inlet bulk velocity of the air $(\mathrm{U} \equiv \mathrm{V} 2)$.

\section{A. Axial velocity}

The results obtained for the axial velocity of methane and propane in the various stations $\mathrm{x} / \mathrm{R}=0.38$ and $x / R=4.67$ are shown in figure 2 . The large velocity values are those in the flame zone. It can be observed that the radial profiles of the axial velocity of two fuels have the same tendency, when the difference between the two profiles is small is given by $7 \%$. The high air velocity axial velocity values presented by the peaks in the $\mathrm{x} / \mathrm{R}=0.38$ and $\mathrm{x} / \mathrm{R}=4.67$ stations, where it is in the flame area. The zone where the velocities are negative presents the recirculation zone generated by sudden widening of the burner and the shear of the delayed flow of the fuel. The increase in speed is justified by the existence of the flame in this region. We can also see negative values in the velocity profiles which show the recirculation regions: in the center of the burner and close to the walls. It is observed that the velocity of the methane is greater than the propane velocity caused by the molar mass of methane below the mass of propane.

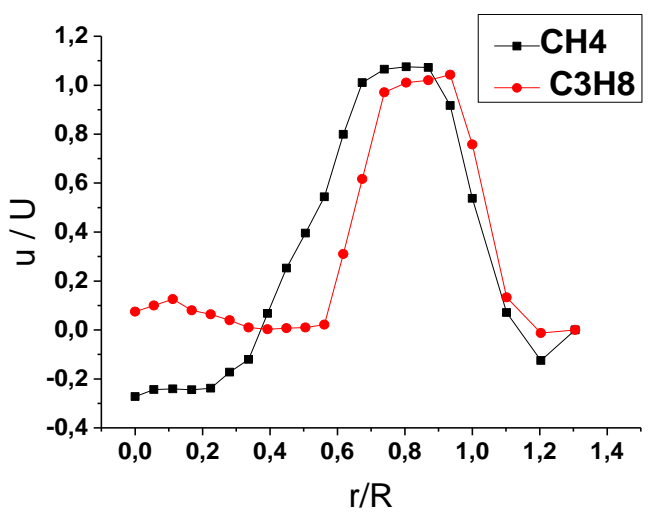

a) $\mathrm{x} / \mathrm{R}=0.89$

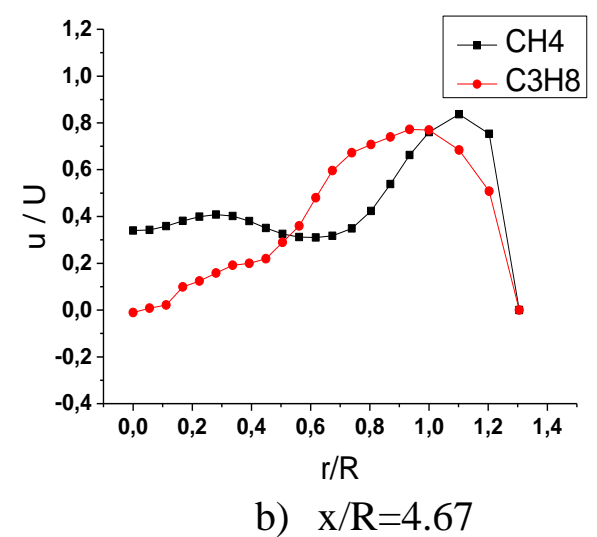

Figure 2. Comparison of the axial velocity between $\mathrm{CH} 4$ and $\mathrm{C} 3 \mathrm{H} 8$

\section{B. Temperature}

Figure 3 shows the difference in temperature distributions between $\mathrm{CH}_{4}$ and $\mathrm{C}_{3} \mathrm{H}_{8}$ in a combustion chamber. The radial temperature profiles have the same trend for both fuels with the difference of $5 \%$. The stations $x / R=1.57$ and $x / R=5.20$ are situated in the region of the combustion chamber, ie close to the fuel and oxidizer zone, which justifies the decrease in the temperature downstream report. The temperature takes maximum values at the center of the combustion chamber because this zone is the same zone of chemical reactions and these reactions are considered as exothermic reactions. This is called the hot zone where chemical reactions and soot formation generate radiation accumulation, which means an increase in temperature in these areas. In the region of the flame, the temperature profiles show by the peaks in the stations defined by $\mathrm{x} / \mathrm{R}=1.57$ and $\mathrm{x} / \mathrm{R}=5.20$, and then decrease to equal the wall temperature equal to $\mathrm{T}=500 \mathrm{~K}$. The values of the 
temperature decreases as we move away from the flame area. The observed shift of $\mathrm{C}_{3} \mathrm{H}_{8}$ and $\mathrm{CH}_{4}$ temperatures obtained by calculations is owed to the molar masses difference between theses fuels, since the chemical composition is the key parameter in rising combustion temperatures.

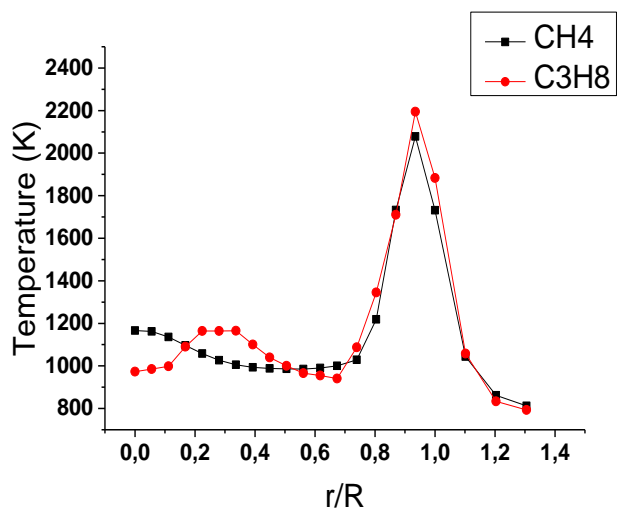

a) $\mathrm{x} / \mathrm{R}=1.57$

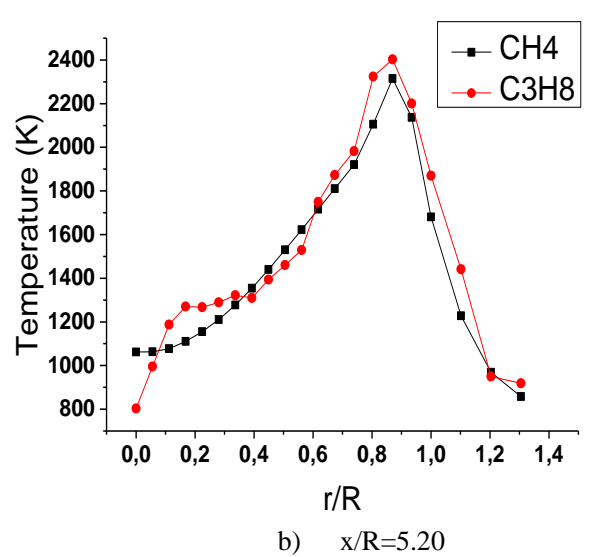

Figure 3. Comparison of the temperature between $\mathrm{CH} 4$ and $\mathrm{C} 3 \mathrm{H} 8$

\section{Mass fraction of carbon monoxide}

Figure 4 shows a comparison between the mass fraction of $\mathrm{CO}$ resulting from the combustion of methane and propane. The radial profiles of the mass fraction of carbon monoxide present by the stations defined by $\mathrm{x} / \mathrm{R}=3.84$ and $\mathrm{x} / \mathrm{R}=7.41$. The mass fraction of the chemical species may be provided to behave in the same manner as the temperature. The difference between the two profile curves of the mass fraction of $\mathrm{CO}$ resulting from $\mathrm{CH}_{4}$ and $\mathrm{C}_{3} \mathrm{H}_{8}$ is about $3 \%$. In stations $\mathrm{x} / \mathrm{R}=3.84$ and $\mathrm{x} / \mathrm{R}=7.41$ : the mass fraction values in these stations are relatively high, which is reflected by high combustion efficiency at these stations. It is always found that the fractions are elevated at the center of the combustion chamber because it is the reaction zone where the production of chemical species. In general, the results clearly show that the carbon monoxide $\mathrm{CO}$ value of propane is high than methane.

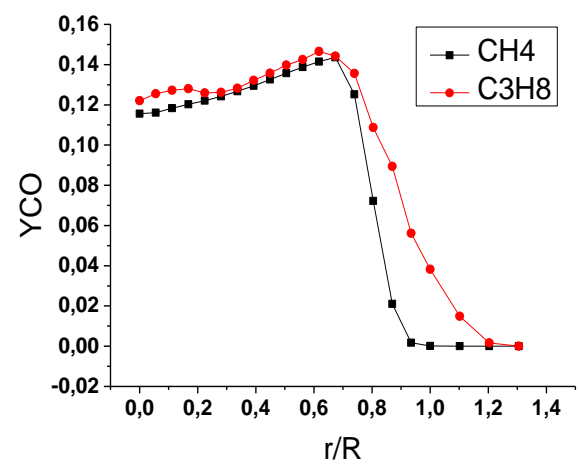

a) $\mathrm{x} / \mathrm{R}=3.84$

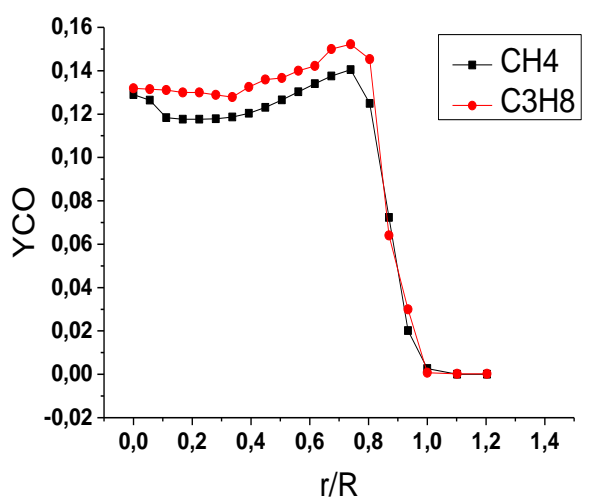

b) $\mathrm{x} / \mathrm{R}=7.41$

Figure 4. Comparison of the mass fraction of $\mathrm{CO}$ between $\mathrm{CH} 4$ and $\mathrm{C} 3 \mathrm{H} 8$

\section{CONCLUSION}

In this study, we summarize the validation of the coupled LES/PDF models and the effect of the methane and propane input behavior supplied to the combustion chamber, using the FLUENT-CFD package to perform the calculations. The conclusions of this inquiry are as follows:

- The relationship between temperature and carbon monoxide is proportional.

- Generally, a certain temperature discrepancy between the studied fuels was observed in different stations, which can be owed to the molar masse role played in combustion flame temperatures.

- The higher temperature for propane fuel versus methane fuel, at different stations.

- The methane velocity is faster than that of propane since the molar mass of methane is smaller than propane.

- The $\mathrm{CH}_{4}$ fuel gives a good result reduces the $\mathrm{CO}$ emission in the species produced by the combustion of $\mathrm{C}_{3} \mathrm{H}_{8}$.

With these results, we conclude that methane fuel is better than propane, which is cleaner and less harmful to the environment compared to propane. 


\section{REFERENCES}

[1] M.E.H. Attia, “Etude de l'Effet de l'Injection de $\mathrm{H}_{2}$ sur une Flamme Non Prémélangée," Ph.D. Thesis, University of Tébessa, Algeria 2017.

[2] F. Bouras, "Étude de la combustion turbulente via des fonctions de densité de probabilité. . Ph.D. Thesis, University of HL Batna, Algeria 2011.

[3] F. Bouras, M.E.H.Attia, F. Khaldi and M. SIAMEUR. "Control of the Methane Flame Behavior by the Hydrogen Fuel Addition: Application to Power Plant Combustion Chamber," International journal of Hydrogen energy, vol. 42, pp. 89328939, 2017.

[4] F. Bouras, M.E.H. Attia, F. Khaldi and M. SIAMEUR. "Control of the Methane Flame Behavior by the Hydrogen Fuel Addition: Application to Power Plant Combustion Chamber," Proceedings of Engineering \& Technology (PET). IPCO-2016, vol. 13, $\quad$ pp.114-118, 2016. http://ipco.com/PET_Journal/PET_CurrentIssue.ht $\underline{\mathrm{ml}}$

[5] F. Bouras, A. Soudani, and M. Si Ameur, "Thermochemistry Study of Internal Combustion Engine,” Energy Procedia, vol.18, pp. 1086-1095, 2012.

[6] F. Bouras, A. Soudani, and M. Si Ameur, "BetaPDF Approach for Large Eddy Simulation of Nonpremixed Turbulent Combustion, International Review of Mechanics Engineering," vol. 4, pp. 1096-1099, 2010.

[7] C. P. Pierce, P. Moin, "Progress-Variable Approach for Large-Eddy Simulation of Non-Premixed Turbulent Combustion," Journal of Fluid Mechanics, vol. 504, pp 73-97, 2004.

[8] F. Bouras, M.E.H. Attia and F. Khaldi, "Entropy Generation Optimization in Internal Combustion Engine," Environ. Process, vol. 02, pp. 233-242, 2015.

\section{NOMENCLATURE}

$\mathrm{R}$ Constant of ideal gas

$\left[\mathrm{J} . \mathrm{kg}^{-1} \cdot \mathrm{K}^{-1}\right]$

$\mathrm{R}, \mathrm{r}$ Radius

[m]

$\mathrm{T}$ Temperature

Axial velocity

$\mathrm{x}$ Cartesian coordinate [m]

$[\mathrm{K}]$

$\left[\mathrm{m} . \mathrm{s}^{-1}\right]$

$\mathrm{y}$ Mass fraction of chemical [\%] species

Greeks symbols

$\alpha \quad$ Thermal Diffusivity $\quad\left[\mathrm{m}^{2} \cdot \mathrm{s}^{-1}\right]$

$\rho \quad$ Density

$\varepsilon \quad$ Dissipation of energy

$\left[\mathrm{kg} \cdot \mathrm{m}^{-3}\right]$

Arrhenius terms

$\left[\mathrm{m}^{2} \cdot \mathrm{s}^{-3}\right]$

$\left[\mathrm{s}^{-1}\right]$

$\lambda$ Thermal conductivity

$\left[\mathrm{kW} \cdot \mathrm{m}^{-1} \cdot \mathrm{K}^{-1}\right]$

$\mu \quad$ Chemical potential, Viscosity

$\mathrm{N}$ Number of chemical species

$\left[\mathrm{kg} \cdot \mathrm{m}^{-1} \cdot \mathrm{s}^{-1}\right]$

$\mathrm{i}, \mathrm{j}, \mathrm{k} \quad$ Indices of Cartesian coordinate 